\title{
El jugo de manzana y otros líquidos administrados para el tratamiento de gastroenteritis leve en niños fueron no inferiores a las sales de rehidratación oral
}

\author{
Apple juice and other fluids administered for the treatment of mild gastroenteritis in children were not inferior to the
}

electrolyte maintenance solution

Freedman S, y col. JAMA. 2016 ;315(18):1966-1974

\section{Comentado de:}

Freedman S, y col. JAMA. 2016 ;315(18):1966-1974'.

\section{Objetivo}

Determinar si la hidratación oral con jugo de manzana diluido y/o líquidos a elección no es inferior a las sales de rehidratación oral (SRO) en niños con gastroenteritis leve.

\section{Diseño, lugar y pacientes}

Ensayo clínico aleatorizado, de no inferioridad, simple ciego. Realizado en un departamento de urgencias pediátricas en Toronto, Ontario, Canadá. Los participantes fueron niños de 6 a 60 meses con gastroenteritis y deshidratación leve.

\section{Intervención}

Los participantes fueron asignados aleatoriamente para recibir jugo de manzana diluido $(n=323)$ o SRO con sabor a manzana $(n=324)$. La terapia de rehidratación oral siguió los protocolos institucionales. Después del alta, el grupo jugo de manzana diluido utilizó fluidos a elección. El grupo de SRO reemplazó las pérdidas sólo con SRO. El cegamiento fue de los investigadores y de aquellos que repartían los líquidos en la central de emergencias.

\section{Medición de resultados principales}

Se realizó un análisis por intención de tratar. El resultado primario fue compuesto, definiendo "falla de tratamiento" como cualquiera de los siguientes resultados dentro de los siete días de inicio de tratamiento: requerimiento de hidratación por vía endovenosa, hospitalización, nueva consulta médica no programada, síntomas prolongados, cambio de grupo de tratamiento (crossover), pérdida de peso del $3 \%$ o deshidratación significativa. E margen de no inferioridad se definió como una diferencia entre los grupos de $7,5 \%$ para el resultado primario y se evaluó con un $\alpha$-lado $\alpha=0,025$.

\section{Resultados principales}

Los resultados principales se resumen en la Tabla 1

Tabla 1. Resultado compuesto en los grupos de estudio. Notas: IC $95 \%$ : intervalo de confianza del $95 \%$.

\begin{tabular}{|c|c|c|c|c|c|c|}
\hline \multirow[t]{2}{*}{ Resultados } & \multicolumn{2}{|c|}{ Grupo jugo de manzana } & \multicolumn{2}{|c|}{ Grupo sales de rehidratación } & Diferencia & valor $p$ \\
\hline & $\mathrm{n} /$ total & $\%($ IC $95 \%)$ & $\mathrm{n} /$ total & $\%($ IC $95 \%)$ & $\%($ IC $95 \%)$ & \\
\hline $\begin{array}{l}\text { Resultado primario compuesto (cualquier } \\
\text { criterio) }\end{array}$ & $54 / 323$ & $\begin{array}{c}16,7 \\
(12,8 \text { a } 21,2)\end{array}$ & $81 / 324$ & $\begin{array}{l}25,0 \\
(20,4 \text { a } 30,1)\end{array}$ & $\begin{array}{l}-8,3 \\
(- \text { infinito a }-2,0)\end{array}$ & $<0,001$ \\
\hline
\end{tabular}

\section{Conclusiones}

Entre los niños con gastroenteritis leve y deshidratación leve, la hidratación oral inicial con jugo de manzana diluido seguido de líquidos a elección, en comparación con las SRO, produjo menos fallas de tratamiento.

Fuente: Physician Services Incorporated Foundation.

\section{Comentario}

En Argentina los casos de gastroenteritis en la infancia llegan a casi 100.000 eventos por año, representando el $40 \%$ de las internaciones en la primera infancia. Se sabe que la causa más frecuente es viral y por lo tanto el cuadro se autolimita. Sin embargo, la complicación más temida es la deshidratación ${ }^{2}$.

En el presente estudio la escala de deshidración utilizada (Clinical Dehidration Scale) evalúa cuatro características clínicas (apariencia general, ojos, lengua o mucosas, y lágrimas) y otorga un puntaje posible de 0 a 8 , correspondiendo 0 a una normal hidratación, 1 a 4 a deshidratación leve (o mínima) y 5 a 8 a deshidratación moderada a severa ${ }^{3}$.

Las SRO son una de las indicaciones para el inicio del tratamiento. A pesar de su utilidad, las SRO tienen muy mala adherencia por parte de los niños debido a su sabor ${ }^{4}$. En encuestas previamente realizadas, los cuidadores de los niños preferían la hidratación endovenosa a las $\mathrm{SRO}^{5}$. Es por esto, que la necesidad actual es buscar nuevos recursos para la rehidratación de los pacientes pediátricos a fin de evitar complicaciones mayores. Encontrar evidencia acerca de la rehidratación de niños con los líquidos que ellos prefieran, nos permite indicar tratamientos más sencillos, más baratos, con mejor adherencia y menos complicaciones posteriores. 
Por último, cabe destacar que el trabajo fue realizado en poblaciones con altos ingresos y no se encuentra disponible el detalle de cómo fueron preparadas las soluciones de jugo de manzana, por lo cual no podría recomendarse un tratamiento estándar ni su extrapolación a nuestra población.

\section{Conclusiones del comentador}

Este ensayo clínico plantea que la hidratación a niños con gastroenteritis leve podría realizarse tanto con SRO como con jugo de manzana y líquidos a elección. Esto sustenta la idea de que el tratamiento adecuado es prevenir la deshidratación de los niños permitiendo que ellos se hidraten con aquellos líquidos que prefieran. En otras palabras, la indicación médica tiene que ser fuerte respecto de la hidratación de los niños con gastroenteritis leve no complicada, independientemente de los líquidos que se utilicen.

Micaela Alurralde [ Servicio de Medicina Familiar y Comunitaria, Hospital Italiano de Buenos Aires micaela.alurralde@hospitalitaliano.org.ar ]

Alurralde M. El jugo de manzana y otros líquidos administrados para el tratamiento de gastroenteritis leve en niños fueron no inferiores a las sales de rehidratación oral. Evid Actual Pract Ambul. 2019;22(04):e001099. Comentado de: Freedman, S; Willan, A; Boutis, K; Schuh, S. Effect of Dilute Apple Juice and Preferred Fluids vs Electrolyte Maintenance Solution on Treatment Failure Among Children With Mild Gastroenteritis. A Randomized Clinical Trial. JAMA. 2016;315(18):1966-1974. doi:10.1001/jama.2016.5352. PMID: 27131100

\section{Referencias}

1. Freedman SB, Willan AR, Boutis K, Schuh S. Effect of dilute apple juice and preferred fluids vs electrolyte maintenance solution on treatment failure among children with mild gastroenteritis: A randomized clinical trial. JAMA - Journal of the American Medical Association. 2016;315(18):1966-1974. Available from: 10.1001/jama.2016.5352.

2. de Infectología CN. Gastroenteritis por rotavirus y su prevención. Archivos argentinos de pediatría. 2006;104(6):554-559. null. Available from: https://www.sap.org.ar/docs/profesionales/consensos/v104n6a12.pdf.

3. Tam RK, Wong H, Plint A, Lepage N, Filler G, et al. Comparison of clinical and biochemical markers of dehydration with the clinical dehydration scale in children: a case comparison trial. BMC Pediatrics. 2014;14(1):149. Available from: 10.1186/1471-2431-14-149.

4. Reis EC, Goepp JG, Katz S, Santosham M, et al. Barriers to use of oral rehydration therapy. Pediatrics. 1994;93(5):708-711.

5. Karpas A, Finkelstein M, Reid S, et al. Parental preference for rehydration method for children in the emergency department. Pediatric Emergency Care. 2009;25(5):301-306. Available from: 10.1097/PEC.0b013e3181a34144. 